\title{
BULLYING MENINGKATKAN KECEMASAN SISWA SMK MUHAMMADIYAH 1 PADANG RATU LAMPUNG TENGAH
}

\author{
BULLYING INCREASES ANXIETY IN STUDENTS OF SMK MUHAMMADIYAH 1 \\ PADANG RATU, CENTRAL LAMPUNG
}

\author{
${ }^{1}$ Nuria Muliani, Alfiyan Prima Ginanjar ${ }^{2}$, Yusnita $^{3}$ \\ ${ }^{1}$ Fakultas Kesehatan Universitas Muhammadiyah Pringsewu \\ Email: nuriamuliani@yahoo.com
}

\begin{abstract}
Bullying Increases Anxiety in Students of SMK Muhammadiyah 1 Padang Ratu, Central Lampung. Bullying is an abuse of power or power committed by a person or group. Victims of bullying can feel anxious, unpleasant fear that is often accompanied by physiological symptoms, emotional responses to subjective individual judgments. The purpose of this study was to determine the relationship of bullying behavior to the level of student anxiety in SMK Muhammadiyah 1 Padang Ratu, Central Lampung in 2019. This study used a correlation study with a cross sectional approach. The subjects of this study were grade $\mathrm{X}$ students of SMK Muhammadiyah 1 Padang Ratu, Central Lampung ... The number of samples was 102 respondents. The sampling technique uses total sampling. The instruments used were bullying behavior questionnaire and Hamilton Anxiety Rating Scale (HARS). The statistical test used is the Chi Square test. The results obtained are that there is a relationship between bullying behavior and the level of student anxiety in SMK Muhammadiyah 1 Padang Ratu Lampung in 2019 with a p-value of $0.013(<0.05)$ with an odd ratio value $(\mathrm{OR}=3.045)$. Health workers need to provide information about bullying behavior and anxiety levels in order to help students who experience bullying behavior and be able to control anxiety levels properly.
\end{abstract}

Keywords : Bullying, Anxienty

\begin{abstract}
Abstrak: Bullying Meningkatkan Kecemasan Siswa SMK Muhammadiyah 1 Padang Ratu Lampung Tengah. Bullyingmerupakan penyalahgunaan kekuatan atau kekuasaan yang dilakukan oleh seseorang atau kelompok.Korban bullying dapat merasa cemas, takut yang tidak menyenangkan yang sering disertai gejala fisiologis, respon emosional terhadap penilaian individu yang subjektif. Tujuan penelitian ini untuk mengetahui hubungan perilaku bullying terhadap tingkat kecemasan siswa di SMK Muhammadiyah 1 Padang Ratu Lampung Tengah Tahun 2019.Penelitian ini menggunakan studi korelasi dengan pendekatan cross sectional. Subjek penelitian ini merupakan siswa kelas X SMK Muhammadiyah 1 Padang Ratu Lampung Tengah..Jumlah sampel sebanyak 102 responden. Teknik sampling menggunakan total sampling.Instrumen yang digunakan adalah kuisioner perilaku bullying dan Hamilton Anxiety Rating Scale (HARS).Uji Statistik yang digunakan uji Chi Square. Hasil penelitian yang didapat yaitu terdapathubungan antara perilaku bullying dengan tingkat kecemasansiswa di SMK Muhammadiyah 1 Padang Ratu Lampung Tahun 2019 dengan nilai $p$-value 0,013 $(<0,05)$ dengan nilai odd ratio $(\mathrm{OR}=3.045)$. Tenaga kesehatan perlu memberikan informasi mengenai perilaku bullying dan tingkat kecemasan agar dapat membantu siswa yang mengalami perilaku bullyingdan dapat mengontrol tingkat kecemasan dengan baik.
\end{abstract}

Kata Kunci :Bullying, Kecemasan

\section{PENDAHULUAN}

Masa remaja adalah periode kehidupan yang penuh dengan dinamika, dimana pada masa tersebut terjadi perkembangan dan perubahan yang sangat pesat. Pada saat ini remaja mempunyai risiko tinggi terhadap gangguan tingkah laku, kenakalan dan terjadinya kekerasan baik sebagai korban maupun sebagai pelaku dari tindak kekerasan. (Sari Pediatri, 2010).

Tindakan kekerasan pada pelajar lebih dikenal dengan istilah bullying yang pada umumnya disebabkan oleh senioritas sebagai salah satu perilaku "bullying", seringkali justru diperluas oleh siswa sendiri sebagai kejadian yang bersifat laten. Senioritas dilanjutkan untuk hiburan, penyaluran dendam, iri hati, atau mencari popularitas, melanjutkan tradisi atau 
untuk menunjukkan kekuasaan. Perilaku ini diperparah dengan tidak jelasnya tindakan dari para guru dan pengurus sekolah. Sebagian guru cenderung "membiarkan", sementara sebagian yang lain melarang tindakan bullying" (Astuti, 2008, dalam Ela dkk, 2017).

Kasus bullying pada anak merupakan fenomena gunung es, kasus yang mencuat terlihat sedikit, namun faktanya sangat banyak, mengakar, terwariskan dari generasi ke generasi. Kasus bullying sering terjadi pada rentang usia 11 - 20 tahun khususnya pada SLTA,pada usia inilahkasus bullying kurang mendapat perhatian lebih, karena dianggap hal yang wajar. Seringkali anak saling mengejek namun kondisi ini seringkali tak terpantau dan lepas dari perhatian orang tua, guru bahkan orang sekitar. Kebanyakan guru, orangtua berfikir bahwa bullying yang terjadi pada anak hanyalah masalah kecil dan tak berdampak negatif (Elvigro, 2014).

Aktivis yayasan Semai Jiwa Amini, mengemukakan bullying adalah sebuah situasi dimana terjadi penyalahgunaan kekuatan /kekuasaan untuk menyakiti seseorang atau sekelompok sehingga korban merasa tertekan, trauma, dan tidak berdaya. Sedangkan bullying yang paling sering terjadi pada usia sekolah SLTA yaitubullying verbal seperti memberikan julukan nama, celaan, fitnah, penghinaan, menuduh, menyoraki, memaki, mengolok-olok, serta menebar gosip(Sejiwa, 2008, dalam Ela dkk, 2017).

Remaja yang menjadi korban bullying dapat mengalami perasaan takut, cemas, marah, tak berdaya,kesepian, serta keinginan untuk bunuh diri. Korban bullying juga lebih cenderung untuk bolos karena takut pergi kesekolah, sehingga banyak korban bullying yang pada akhirnya mengalami putus sekolah, sehingga hal ini memerlukan penanganan lebih lanjut (Prasetyo, 2011).

Dampak bagi pelaku bullying National Youth Violence Prevention mengemukakan bahwa pada umumnya, para pelaku ini memiliki rasa percaya diri yang tinggi dengan harga diri yang tinggi pula, cenderung bersifat agresif dengan perilaku yang pro terhadap kekerasan, tipikal orang berwatak keras, mudah marah dan impulsif, toleransi yang rendah terhadap frustasi. Jika dibiarkan terus-menerus tanpa intervensi, perilaku bullying ini dapat menyebabkan terbentuknya perilaku lain berupa kekerasan terhadap anak dan perilaku kriminal lainnya (Astuti, 2008, dalam Ela dkk, 2017).

DataUNICEFtahun 2018 menyebutkan, $50 \%$ dari remaja di dunia mengalami kekerasan di lingkungan sekolah. Laporan yang baru saja dipublikasikan itu menyatakan, sebanyak $50 \%$ siswa berusia 13-15 tahun atau setara 150 juta remaja di dunia pernah mengalami kekerasan berupa perkelahian fisik serta perundungan atau bullying dari teman sebaya di sekolah. Secara global, laporan UNICEF menemukan 720 juta anak usia sekolah tinggal di negara yang tidak melindungi mereka dari hukuman fisik di institusi pendidikan."Sekolah tidak menjadi tempat aman sebagaimana mestinya, karena perundungan, karena hukuman fisik oleh guru, dan serangan terhadap sekolah," kata penasihat senior UNICEF, Claudia Cappa. (CNN Indonesia, 2018).

Menurut KPAI, saat ini kasus bullying menduduki peringkat teratas pengaduan masyarakat. Dari 2011 hingga agustus 2014, KPAI mencatat 369 pengaduan terkait masalah tersebut. Jumlah itu sekitar $25 \%$ dari total pengaduan di bidang pendidikan sebanyak 1.480 kasus. Bullying yang disebut KPAI sebagai bentuk kekerasan di sekolah, mengalahkan tawuran pelajar, diskriminasi pendidikan, ataupun aduan pungutan liar (republika, rabu 15 oktober 2014). KPAI menemukan bahwa anak mengalami bullying di lingkungan sekolah sebesar (87.6\%), dari angka $(87.6 \%)$ tersebut, (29.9\%) bullying dilakukan oleh guru, (42.1\%) dilakukan oleh teman sekelas, dan $(28.0 \%)$ dilakukan oleh teman lain kelas (Prima, 2012).

Seorang siswa perempuan kelas X SMAN I Gunungsugih kabupaten Lampung Tengah berusia 15 tahun, menjadi korban pengeroyokan enam siswi lainnya. Akibatnya, korban menderita gegar otak dan luka serius di sekujur badan, korban masih harus menjalani perawatan di RS Harapan Bunda. Siswa yang masih berbicara terbata-bata karena luka mengatakan pengeroyokan terhadap dirinya bermula dari kesalah pahaman dengan seorang temannya, tentang peminjaman baju seragam (Tribun Lampung, 2016).

Berdasarkan hasil pra survey yang dilakukan pada tanggal 21 maret 2019 di SMK Muhammadiyah 1 Padang Ratu Lampung Tengah dari hasil wawancara guru BK (Bimbingan Konseling) mengatakan terdapat tindakan bullying,kasus bullying yang terbanyak di SMK Muhammadiyah Padang Ratu adalah bullying verbal, dan paling sering terjadi tindakan adalah siswa kelas $\mathrm{X}$ di karenakan senioritas dilingkungan sekolah. Selanjutnya dari hasil wawancara pada 7 siswa yang di wawancara di dapat hasil 4 siswa mengatakan pernah megalami tindakan bullying 
verbalseperti memberikan julukan nama, celaan, penghinaan, menuduh, menyoraki, memaki, mengolok-olok, serta menebar gosip. 3 siswa mengatakan pernah melakukan dan melihat tindakan bullying verbal seperti memberikan julukan nama,celaan, penghinaan, menuduh, menyoraki, memaki, mengolok-olok, serta menebar gosipyang di lakukan dilingkungan SMK Muhammadiyah 1 Padang Ratu. 4 siswa yang penah mengalami tindakan bullying mengatakan takut, sesekali napas pendek, jantung berdebar, gemetar, perasaan tidak tenang merasa terancam, dan trauma jika bertemu dengan siswa yang mem bully nya. Bahaya bullying verbal jika tidak teratasi maka siswa lebih cenderung untuk bolos karena takut pergi kesekolah, sehingga banyak korban bullying verbal yang pada akhirnya mengalami putus sekolah. Penelitian ini bertujuan untuk mengetahui hubungan Perilaku Bullying Terhadap Tingkat Kecemasan Siswadi SMK Muhammadiyah 1 Padang Ratu Lampung Tengah Tahun 2019”.

\section{METODE}

Desain yang digunakan dalam penelitian ini adalah survey analitik dengan pendekatan crossectional. Pada penelitian ini jumlah sampel adalah seluruh siswa kelas $\mathrm{X}$ di SMK Muhammadiyah 1 Padang Ratu Lampung Tengah. Tekhnik pengambilan sampel pada penelitian ini menggunakan total sampling. Sehingga sampel yang diambil berjumlah 102 siswa. Kriteria inklusi dalam penelitian ini sebagai berikut: Semua siswa kelas X di SMK Muhammadiyah 1 Padang Ratu Lampung Tengah, Bersedia menjadi responden, laki-laki maupun perempuan, Hadir saat penelitian berlangsung. alat ukur kecemasanHamilton Anxiety Rating Scale (HARS) dengan penilaian hasil yaitu menjumlahkan dari masing masing nilai angka dari 14 kelompok gejala tersebut maka akan diketahui derajat kecemasan. Untuk menguji variabel bebas dan variabel terikat dapat dilakukan dengan uji statistic chi square dengan alpha $5 \%$.

\section{HASIL}

1. Analisis Univariat

Dari variabel perilaku bullying dikategorikan menjadi mengalami dan tidak mengalami, diperoleh hasil distribusi yang dapat dilihat pada tabel dibawah ini

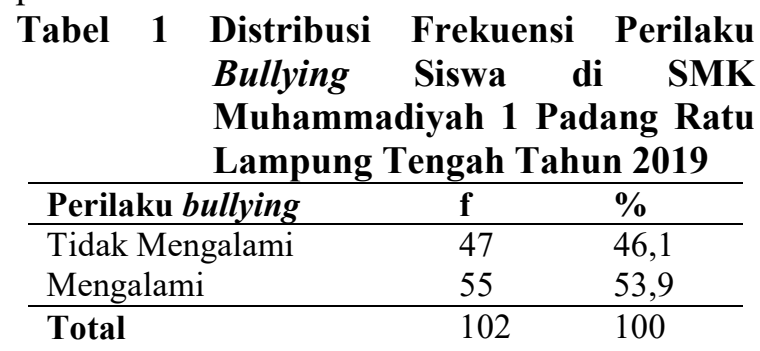

Dari tabel 1 dapat dijelaskan bahwa dari 102 responden sebagian besar mengalami perilaku bullyingyaitu sebanyak 55 responden (53.9\%).

Dari variabel tingkat kecemasan dikategorikan menjadi ringan dan sedang, diperoleh hasil distribusi yang dapat dilihat pada tabel dibawah ini :

Tabel 2 Distribusi Frekuensi Tingkat Kecemasan Siswa Di SMK Muhammadiyah 1 Padang Ratu Lampung Tengah Tahun 2019

\begin{tabular}{lll}
\hline Tingkat Kecemasan & f & \% \\
\hline Ringan & 57 & 55,9 \\
Sedang & 45 & 44,1 \\
\hline Total & 102 & 100
\end{tabular}

Dari tabel 2 dapat dijelaskan bahwa dari 102 responden sebagian besar mengalami tingkat kecemasan ringan yaitu sebanyak 57 responden ( $55.9 \%)$.

2. Analisis Bivariat

Analisis bivariat untuk melihat hubungan perilaku bullying dengan tingkat kecemasan siswa di SMK Muhammadiyah 1 Padang Ratu Lampung Tengah Tahun 2019, adalah sebagai berikut :

Tabel 3 Hubungan Perilaku Bullying Dengan Tingkat Kecemasan Siswa Di SMK Muhammadiyah 1 Padang Ratu Lampung Tengah Tahun 2019

\begin{tabular}{lccccccc}
\hline \multirow{2}{*}{ Perilaku bullying } & \multicolumn{6}{c}{ Tingkat Kecemasan } & \multirow{2}{*}{ P value } \\
\cline { 2 - 6 } & \multicolumn{2}{c}{ Ringan } & \multicolumn{2}{c}{ Sedang } & \multicolumn{2}{c}{ Total } & \\
\cline { 2 - 6 } Tidak Mengalami & $\mathbf{N}$ & $\mathbf{\%}$ & $\mathbf{N}$ & $\mathbf{\%}$ & $\mathbf{N}$ & $\mathbf{\%}$ & \\
\hline Mengalami & 24 & 70.2 & 14 & 29.8 & 47 & 100 & \multirow{2}{*}{0.013} \\
\hline Jumlah & 24 & 43.6 & 31 & 56.4 & 55 & 100 & 100 \\
\hline
\end{tabular}


Dari hasil analisis pada tabel 4.3 mengenai hubungan perilaku bullying dengan tingkat kecemasan siswa di SMK Muhammadiyah1 Padang Ratu Lampung Tengah, diperoleh bahwa siswa yang tidak mengalami perilaku bullyingsebanyak 47 siswa namun dengantingkat kecemasan ringan sebesar $33(70.2 \%)$ dan tingkat kecemasan sedang sebesar 14 (29.8\%). Siswa yang mengalami perilaku bullying sebanyak 55 dimana siswa dengantingkat kecemasan ringan sebesar $24(43.6 \%)$ dan tingkat kecemasan sedang $31 \quad(56.4 \%)$. Dapat disimpulkan bahwa ada hubungan perilaku bullying terhadap tingkat kecemasan siswa di SMK Muhammadiyah 1 Padang Ratu Lampung Tengah didapatkan Pvalue $0.013(<0.05)$

\section{PEMBAHASAN}

Berdasarkan hasil penelitian dapat disimpulkan bahwa ada hubungan perilaku bullying dengan tingkat kecemasan siswa di SMK Muhammadiyah 1 Padang Ratu Lampung Tengah Tahun 2019, didapatkan Pvalue 0,013 $(<0.05)$.

Sejalan dengan teori yang menyatakan perilaku bullying adalah penggunaan kekuasaan untuk menyakiti seseorang atau sekelompok sehingga korban merasa tertekan, trauma, dan tidak berdaya. Bullying adalah sebuah situasi yang terjadi penyalahgunaan kekuatan atau kekuasaan yang dilakukan oleh seseorang atau kelompok. Pihak yang kuat menekan, memojokan, melecehkan, menyakiti seseorang yang lemah dengan sengaja dan berulang-ulang.

Teori ini juga sejalan dengan data dari KPAI, saat ini kasus bullying menduduki peringkat teratas pengaduan masyarakat. Dari 2011 hingga agustus 2014, KPAI mencatat 369 pengaduan terkait masalah tersebut. Jumlah itu sekitar 25\% dari total pengaduan di bidang pendidikan sebanyak 1.480 kasus. Bullying yang disebut KPAI sebagai bentuk kekerasan di sekolah, mengalahkan tawuran pelajar, diskriminasi pendidikan, atau pun aduan pungutan liar, KPAI menemukan bahwa anak mengalami bullying di lingkungan sekolah sebesar (87.6\%), dari angka (87.6\%) tersebut, (29.9\%) bullying dilakukano leh guru, (42.1\%) dilakukan oleh teman sekelas, dan $(28.0 \%)$ dilakukan oleh teman lain kelas (Prima, 2012).

Sejalan dengan teori kecemasan adalah suatu perasaan takut yang tidak menyenangkan yang sering disertai gejala fisiologis. Menurut Purwanto (2015) kecemasan dapat salah satunya disebabkan karena kaitannya dengan bullying rasa ketakutan, merasa terancam jika bertemu dengan pelaku bullying, dan trauma. Penyebab kecemasan berupa kecemasan interpersonal terjadi dari ketakutan akan penolakan interpersonal yang berhubungan juga dengan trauma masa perkembangan dan teori perilakuyang menyatakan bahwa kecemasan merupakan produk frustasi yaitu segala sesuatu yang mengganggu kemampuan seseorang untuk mencapai sesuatu yang diinginkan.

Berdasarkan penelitian yang dilakukan oleh Lorensia (2015), peneliti menyatakan tidak terdapat hubungan yang signifikan kecemasan sosial. Subjek dalam penelitian ini memiliki kecemasan sosial dalam kategori sedang, namun tidak ditemukan adanya hubungan yang signifikan. Hal tersebut dimungkinkan karena siswa ketika diberikan skala kecemasan sosial, mereka nampak memiliki kecemasan sosial yang berada pada kategori sedang. Apabila mereka mengalami kecemasan sosial maka akan mempengaruhi kepercayaan diri mereka ketika berinteraksi dengan orang lain.

Dalam penelitian, Lorensia (2015) mengaitkan kecemasan sosial pada remaja perempuan korban bullying. Berdasarkan hasil dari penelitian Lorensi (2015), diketahui jika rata-rata subjek memiliki kecemasan sosial dalam kategori sedang Hal ini berarti subjek sudah cukup mampu untuk sekedar berinteraksi dengan orang lain, dan sedikit mengurangi anggapan negatif mereka jika orang lain akan memberikan penilaian yang negatif tentang diri mereka. Maka siswa yang menjadi korbanbullying dengan tingkat kecemasan sosial yang sedang sudah cukup mampu untuk memulai berinteraksi dengan orang lain, karena masih dalam katergori sedang yang berarti mereka juga bisa mengalami tingginya kecemasan sosial, hal ini dikarenakan tingkatan sedang berada diantara tinggi dan rendah. Dalam kehidupan sehari-hari mereka akan cenderung merasa waspada ketika akan berinteraksi dengan orang lain. Selain itu, mereka juga akan sering memberikan penilaian negatif tentang diri mereka sendiri karena merasa tidak mampu atau merasa takut jika apa yang mereka tampilkan tidak sesuai dengan apa yang orang lain pikirkan.

Menurut asumsi peneliti pada penelitian ini banyak siswa yang mengalami perilaku bullying di sekolah khususnya bullying verbal, dan tingkat kecemasan yang terjadi pada siswa lebih banyak pada tingkat kecemasan ringan. Peneliti berpendapat bahwa siswa dalam kategori kecemasan ringan dikarenakan perilaku bullying yang terjadi masih bisa di tangani dengan adanya sarana operasional sekolah seperti UKS (unit kesehatan sekolah), bimbingan konseling yang 
mampu membantu siswa dalam menyelesaikan masalah seperti kasus bullying yang di alami baik di dalam maupun di luar lingkungan sekolah, bullying verbal adalah suatu tindakan yang dilakukan kepada orang lain seperti mengejek, menghina, menjuluki, menebar gosip, dan memfitnah. Sehingga hanya menyakiti perasaan korban bukan menyakiti fisik korban bullying tersebut dan menyebabkan seseorang lebih waspada terhadap orang lain.

Upaya yang harus dilakukan untuk menanggulangi masalah perilaku bullying dan tingkat kecemasan siswa yaitu dengan melakukan sosialisasi oleh tenaga kesehatan tidak hanya kepada siswa namun kepada guru BK agar dapat membantu siswa yang mengalami perilaku bullying agar dapat mengontrol tingkat kecemasan dengan baik dan benar

\section{SIMPULAN}

Distribusi frekuensi perilaku bullying siswa di SMK Muhammadiyah 1 Padang Ratu Lampung Tengah, dari 102 responden sebesar dan sebesar $55(53.9 \%)$ responden mengalami perilaku bullying, sebesar 45 (44.1\%) responden dengan tingkat kecemasan sedang. Ada hubungan perilaku bullying dengan tingkat kecemasan siswa di SMK Muhammadiyah 1 Padang Ratu Lampung Tengah, didapatkan Pvalue 0,013( < $0.05)$.

\section{SARAN}

Diharapkan penelitian ini dapat sebagai bahan masukan dan informasi ataupun untuk meningkatkan pelayanan kesehatan masyarakat, sehingga tenaga kesehatan dapat memberikan pelayanan yang terbaik mengenai hubungan perilaku bullying dengan tingkat kecemasan.

\section{DAFTAR PUSTAKA}

Astuti, P.R. (2008). Meredam Bullying : 3 cara efektif menanggulangikekerasan pada anak. Jakarta: PT. Grasindo.

Elvigro, Paresma. (2014). Secangkir Kopi Bully. Jakarta: PT. Alex Media Komputindo.

Sari pediatri, (2010). Adolescent Development (Perkembangan Remaja). Jakarta : Badan Penerbit Ikatan Dokter Anak Indonesia.
Sejiwa, (2008). Bullying : Mengatasi kekerasan di sekolah dan lingkungan sekitar anak. Jakarta: PT. Grasindo.

Teguh Purwanto. (2015). Buku Ajar Keperawatan Jiwa. Yogyakarta, Pustaka Pelajar

Ela, Sahadi, Meylanny. (2017). Faktor Yang Mempengaruhi Remaja Dalam Melakukan Bullying, Jurnal Penelitian, Departemen Kesejahteraan Sosial FISIP Universitas Padjadjaran.

CNN Indonesia. (2018). UNICEF : Sekolah Tidak Aman bagi Siswa. Di unduh 2019.

https://www.cnnindonesia.com/gayahidup/20180907163958-284328572/unicef-sekolah-tidak-amanbagi-siswa

Athi'. (2017). Pengaruh Tough Stoping Terhadap Tingkat Kecemasan Remaja Yang Mengalami Bullying Di Pesantren, Jurnal Kesehatan, Universitas Pesantren Tinggi Darul 'Ulum, Jombang

Lorensia, (2015). Hubungan Antara Harga Diri dan Kecemasan Sosial Pada Remaja Perempuan Korban Bullying, Jurnal Kesehatan, Universitas Brawijaya, Malang

Prima, Nanda, Nauli, Riri. (2012). FaktorFaktor Yang Berhubungan Dengan Perilaku Bullying Pada Remaja, Jurnal Kesehatan, Universitas Riau. 